\title{
Fracture load and shear stress of prefabricated glass fiber posts
}

\author{
Helder Callegaro Velho ${ }^{1}$, Paolo Baldissara², Jovito \\ adiel Skupien ${ }^{3}$, Vinícius Felipe Wandscher ${ }^{4, *}$
}

${ }^{1}$ School of Dentistry, Franciscan University, Santa Maria, Rio Grande do Sul, Brazil.

${ }^{2}$ Department of Biomedical and Neuromotor Sciences, Unit of Odontostomatological Sciences, Division of Prosthodontics, Alma Mater Studiorum, University of Bologna, Bologna, Italy.

${ }^{3}$ Division of Conservative Dentistry, School of Dentistry, Franciscan University, Santa Maria, Rio Grande do Sul, Brazil.

${ }^{4}$ Division of Prosthodontics, Schoo of Dentistry, Franciscan Unviersity, Santa Maria, Rio Grande do Sul, Brazil.

\section{Corresponding author:}

Vinícius Felipe Wandscher, D.D.S.,

M.Sci.D., Ph.D., Adjunct Professor

Franciscan University

Faculty of Odontology

Prosthodontics-Biomaterials Unit

R. Silva Jardim, 1175, 97010-491,

Rio Grande do Sul State, Santa

Maria, Brazil.

Phone/Fax: +55 5530251202 /

30259002

E-mail:viniwan@hotmail.com

(Dr Vinicius)

Received: January 28, 2019

Accepted: August 20, 2019
Aim: This study evaluated the fracture load and pattern failure of different prefabricated glass fiber posts (GFPs) of the same diameter. Methods: Seventy-eight ( $n=13$ for six groups) GFPs of $1.6 \mathrm{~mm}$ coronal diameter of different brands were evaluated- Exacto (Angelus), Power Post (BM4), White Post DC (FGM), HiRem (Overfibers), Maquira fiber post (Maquira), and Superpost (Supordont). The posts were subjected to fracture load testing $\left(45^{\circ}\right.$ of inclination and $1 \mathrm{~mm} / \mathrm{min}$ until fracture). Each factor (load ( $\mathrm{N}$ ) and shear stress (MPa)) was analyzed separately using one-way ANOVA followed by the Tukey test $(a=0.05)$. Results: The type of failure was evaluated on a stereomicroscope $(\times 10)$. The Power Post samples presented higher values of fracture load $(p<0.001)$ followed by Maquira fiber post, White Post, HiRem, Superpost, and the Exacto posts. The failure pattern observed was intralaminar mode II in-plane shear, such as a failure occur parallel to fibers. Conclusion: Despite the same diameter of GFPs, the fracture load and shear resistance were brand-dependent.

Keywords: Glass. Materials testing. Stress, mechanical. Flexural strength. 


\section{Introduction}

After endodontic treatment on teeth (ETT) with extensive mineral tissue loss, an intraradicular post can improve the retention of the coronal restoration ${ }^{1}$, considering the quantity and quality of the dental remaining ${ }^{2}$. When the remaining is higher than $2 \mathrm{~mm}$, prefabricated glass fiber posts (GFPs) can be used; otherwise, a cast post and core are preferred ${ }^{3}$.

Glass fiber posts are usually used in dentistry because they present adequate adhesion to mono- and dimethacrylates ${ }^{4}$, good aesthetic properties, and clinically higher survival rates ${ }^{5-7}$. The GFPs are composed of unidirectional fibers, lying parallel to each other (carbon, quartz, or glass), and a polymer matrix. The polymer matrix is a highly cross-linked structure composed of epoxy polymers of a high conversion degree ${ }^{8}$. The performance of fibers is influenced by the type, orientation, adhesion to the polymer matrix, and impregnation of the polymer matrix on the fibers ${ }^{9}$.

The fibers are responsible for tensile resistance, whereas the matrix supports the compression stresses ${ }^{10}$. The union between the fibers and the polymer matrix is an important factor that can influence GFP resistance ${ }^{8}$. During the manufacturing process, a silane layer is applied on the fibers (inorganic portion) to improve the adhesion with the resin matrix (organic portion) ${ }^{11}$. Another step in the manufacture of GFPs that improves the mechanical properties is the pretension of fibers. This process occurs before matrix incorporation, enabling fiber resistance at tensile stresses when the post is exposed to bending forces ${ }^{10}$. Wandscher et al. ${ }^{12}$ (2015) showed that the shear stress was similar among fiber posts of different diameters of the same brand when tested with a $45^{\circ}$ loading (except for $1.4 \mathrm{~mm}$ ). Besides, Wandscher et al. ${ }^{13}$ (2016) showed that an endodontically treated tooth restored with fiber post and matalloceramic crown failure with similar characteristics (scallops, consequences by shear stress) at in vitro studies ${ }^{12,14,15}$. So, a sequence of events can lead to the ultimate failure in anterior ETT restored with posts due to shear stresses that is present in the central region of the restorer assembly during the load application, inducing adhesive failures in the post/cement/dentine interfaces ${ }^{16}$. Thus, the question is, which fiber post is less flexible to minimize the shear stresses? GFPs from different manufacturers exhibit a wide variation because of different fabrication processes. Thus, the aim of the present study was to evaluate the fracture load and the pattern failure of different prefabricated GFPs of the same diameter commercially available in the Brazil. The null hypothesis tested was that there is no difference between brands.

\section{Materials and methods}

Seventy-eight GFPs of $1.6 \mathrm{~mm}$ coronal diameter were allocated to six groups $(n=13)$ based on their manufacturer (Table 1). The coronal distance was set to $6 \mathrm{~mm}$ with a digital caliper. The posts were fixed in a parallelometer and embedded in PVC cylinders with a self-cure acrylic resin (VIPI Flash, VIPI, Pirassununga, SP, Brazil) to the reference of $6 \mathrm{~mm}$. 
Table 1. Experimental groups

\begin{tabular}{lcc}
\hline Groups/posts & Brands & Composition* \\
\hline EX & Angelus, Londrina, PR, Brazil & $\begin{array}{c}\text { Glass fiber (80\%) } \\
\text { Epoxy resin (20\%) }\end{array}$ \\
\hline PW & BM4, Maringá, PR, Brazil & N/A \\
\hline WP & FGM, Joinville, SC, Brazil & $\begin{array}{c}\text { Glass fiber (80\%) } \\
\text { Epoxy resin (20\%) }\end{array}$ \\
\hline HR & Overfibers, Mordano, BO, Italy & Fiber Glass (65-72\%) \\
\hline FP & Maquira, Maringá, PR, Brazil & N/A \\
\hline SP & Superdont, Rio de Janeiro, RJ, Brazil & N/A \\
\hline
\end{tabular}

* According to the manufacturers' brochures. N/A-not available.

\section{Fracture loading test}

The specimens were positioned at $45^{\circ}$ (in relation to the horizontal plane) in a universal testing machine (DL-1000, Emic, São José dos Pinhais, Brazil), and a cylindrical piston of planar tip ( $\varnothing: 6 \mathrm{~mm}$ ) applied a load at the rate of $1 \mathrm{~mm} / \mathrm{min}$ on the more coronal portion of the post until fracture. The force $(\mathrm{N})$ on the fracture moment was recorded, and the shear stress ( $\mathrm{MPa}$ ) was calculated according to Wandscher et al. ${ }^{12}$ (2015):

$$
\mathrm{t}=16 F_{\max } \cos 45 / 3 \pi D^{2}(1)
$$

Where $t=$ shear stress, $F_{\text {max }}=$ maximum force to fracture $(N), p=3.14, D p=$ diameter of the specimen.

\section{Failure analysis}

After the fracture loading tests, the samples were submitted to failure analysis on a stereomicroscope (Discovery V20; Carl Zeiss, Germany) on X10. Representative images were observed in scanning electron microscope (SEM) (VEGA3, Tescan).

\section{Statistical analysis}

The mean values of the force/load $(\mathrm{N})$ and the shear stresses (MPa) were analyzed using one-way ANOVA and the Tukey test $(a=0.05)$, after to prove the normal distribution and equality of the data with Shapiro-Wilk and Levene tests, respectively.

\section{RESULTS}

The statistical analysis showed differences between groups, in terms of force values and shear stresses, wherein the PW group exhibited the highest values followed by $F P, W P, H R, S P$ and EX groups $(p<0.0001)$. The fracture load and shear stress values are listed in Table 2.

The pattern of failure is presented in Figure 1 and 2 (stereomicroscope and SEM respectively). It was possible to observe that all specimens fractured with a central longitudinal crack perpendicular to the direction of the applied force. 
Table 2. Fracture load $(\mathrm{N})$ and shear stress $(\mathrm{MPa})$ of the glass fiber posts.

\begin{tabular}{lcc}
\hline \multirow{2}{*}{ Groups } & \multicolumn{2}{c}{ Load/Resistance \pm Standard Deviation* } \\
\cline { 2 - 3 } & Fracture $(\mathbf{N})$ & Shear $(\mathrm{MPa})$ \\
\hline PW & $137.1 \pm 9.5^{\mathrm{a}}$ & $63.7 \pm 4.4^{\mathrm{a}}$ \\
\hline FP & $119.5 \pm 19.6^{\mathrm{b}}$ & $55.5 \pm 9.1^{\mathrm{b}}$ \\
\hline WP & $112.2 \pm 15.7^{\mathrm{b}, \mathrm{c}}$ & $52.1 \pm 7.3^{\mathrm{b}, \mathrm{c}}$ \\
\hline HR & $110.15 \pm 20.4^{\mathrm{b}, \mathrm{c}}$ & $51.2 \pm 9.5^{\mathrm{b}, \mathrm{c}}$ \\
\hline EX & $103.5 \pm 11.6^{\mathrm{b}, \mathrm{c}}$ & $48.1 \pm 5.4^{\mathrm{b}, \mathrm{c}}$ \\
\hline p-value & $100.1 \pm 6.5^{\mathrm{c}, \mathrm{d}}$ & $46.5 \pm 3^{\mathrm{c}, \mathrm{d}}$ \\
\hline
\end{tabular}

*Different letters indicate statistically significant differences. One-way ANOVA was performed separately for fracture and shear stress.
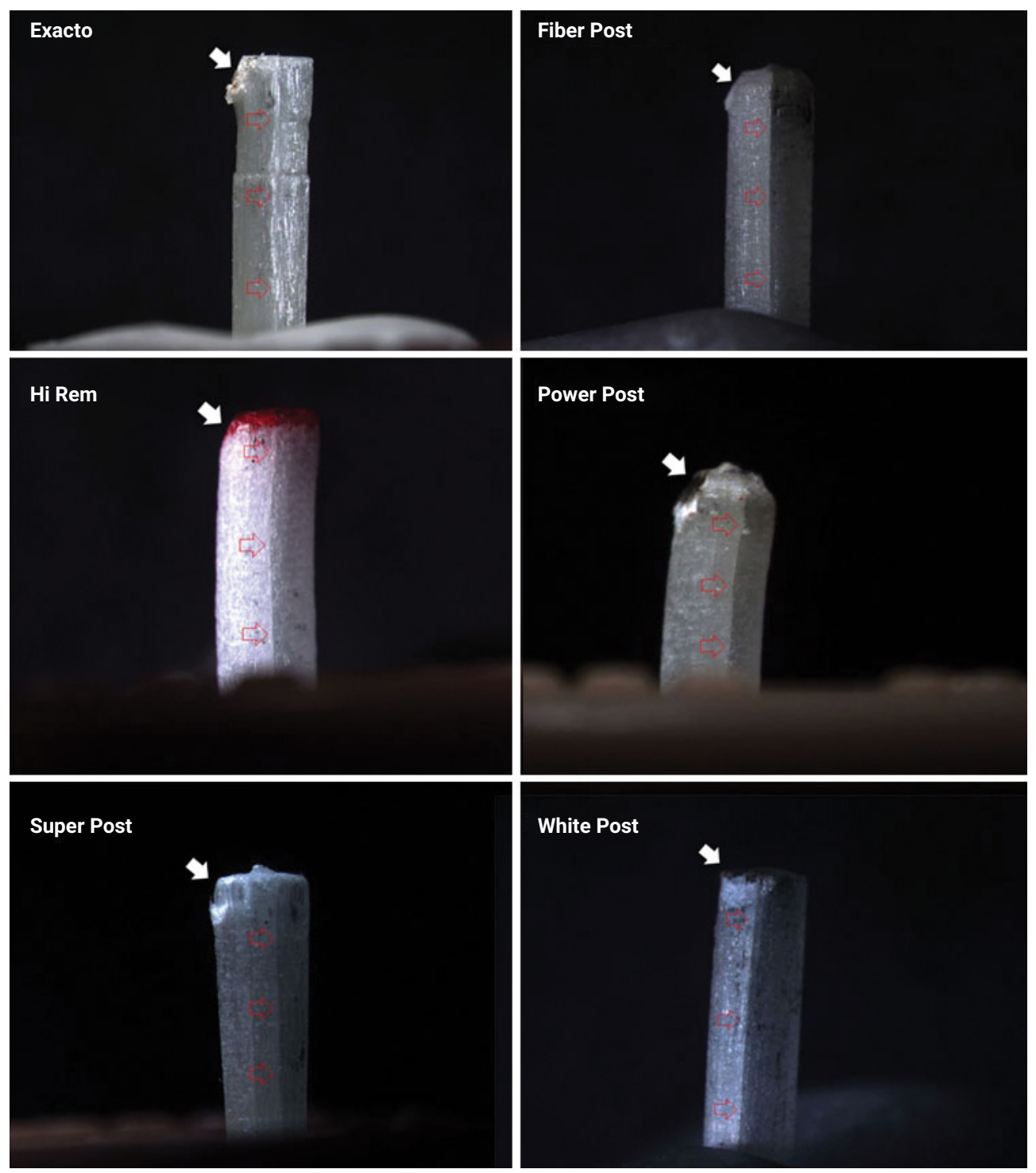

Figure 1. Representative images of the failure pattern. We can observe that the cracks occurs in the center of the specimen (red arrows), which is a characteristic of failure by shear stresses. The white arrow indicates the load application sense. 

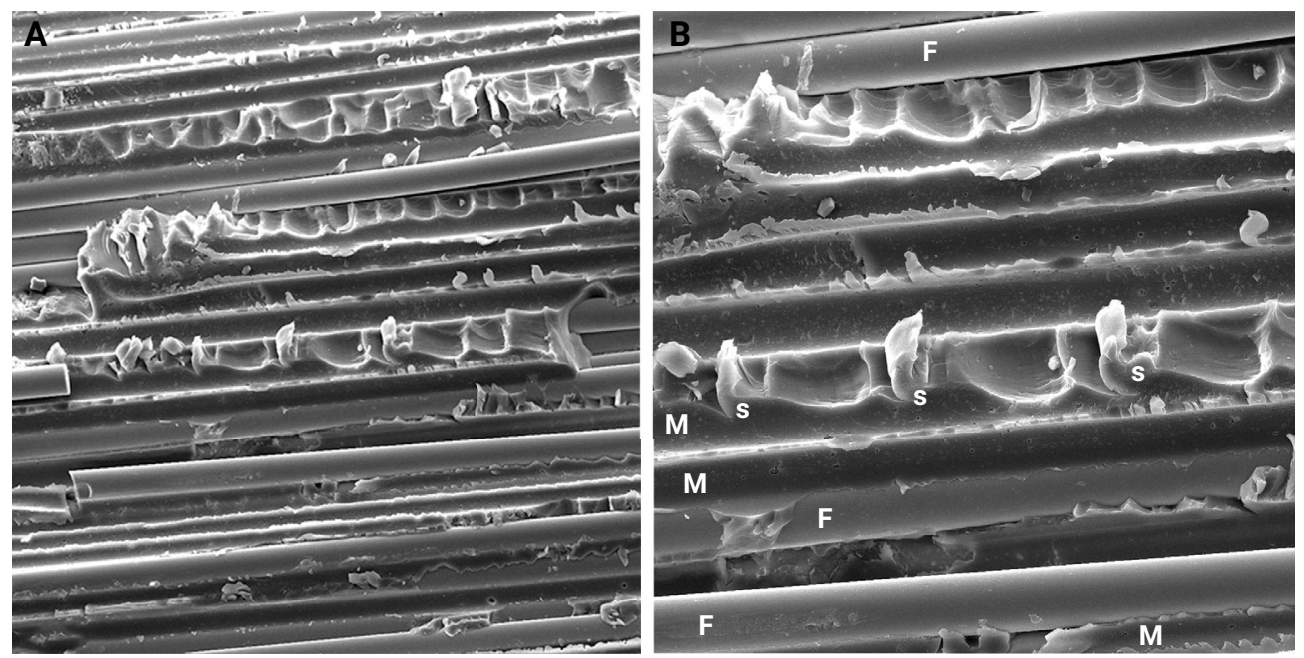

Figure 2. SEM images of the shear failures in the GFPs. A. Representative SEM of the WP group $x 500$. B. SEM (x1000) of the WP group presenting the F: glass fiber, M: epoxy matrix and S: scallops (undulations on the epoxy matrix consequences of the shear stresses).

\section{DISCUSSION}

The results of the current study showed statistical difference between the tested groups; thus, the hypothesis that there is no difference between brands was rejected. The PW group exhibited higher values, and the EX group exhibited smaller values. As the samples were of same diameter and, basically, of the same composition (of glass fiber and epoxy matrix), the difference between groups should be explained by factors such as fiber/matrix proportion, the diameter and pretensioning of the fibers, and fiber/matrix union. In addition, possible errors in the manufacturing process such as bubble incorporation and empty spaces can jeopardize the mechanical properties of GFPs. It may be concluded that the shear stress and diameter are not correlated because the shear values did not change for the different diameters ${ }^{12}$.

However, one factor makes the discussion of the results difficult: the exact composition of the GFP. The difficulty arises especially because some manufacturers do not present this information explicitly. The brochures present only the basic composition (glass fiber and epoxy resin). Data such as fiber diameters, type of glass fibers, pretension of the fibers, and application of a coupling agent (silane) on the fiber are not disclosed. A higher fiber/matrix ratio is reported to generate a higher loading fracture ${ }^{8,17}$. However, if the link between fibers and the matrix is not adequate, no improvement occurs ${ }^{8}$. This fact can explain the small value of the loading found for the EX group, although posts from this group contain $80 \%$ of fibers. Bubbles and empty spaces left during the fabrication process may cause inadequate fiber/matrix union, consequently leading to the formation of structural defects propagating failure ${ }^{18}$

On the other hand, during the fabrication process, fiber treatment can improve the mechanical properties of GFP. Pretension of fibers is one way to achieve it. In this process, the fibers are pretensioned, incorporated into the matrix, and liberated only 
after the complete cure of the epoxy resin. Thus, the fibers are compressed and are able to absorb tensile stresses, when an oblique force is applied ${ }^{10}$. Another possibility is the application of a couple agent on fibers before the matrix incorporation, promoting a better chemical union between the fibers (inorganic portion) and the matrix (organic portion) ${ }^{19}$.

Despite the diameter of the posts being the same, the diameter of the fiber might have influenced our results. Larger diameters may improve the mechanical properties of GFPs $^{20}$, since the distribution of these fibers in the matrix are homogeneous ${ }^{21}$.

With respect to failure pattern, most of the specimens presented a longitudinal crack in the center of the coronal portion (Figure 1) because of shear stresses. These failures, classified as intralaminar mode II in-plane shear, are consequences of two important factors: fiber arrangement (parallel, $0^{\circ}$ ) and shear stress. An important feature are the scallops in the epoxy matrix (figure 2) consequences of the shear stresses in the GFPs. These scallops were founded too in other studies ${ }^{12,13,15}$.

The fracture loading test at $45^{\circ}$ evaluated the resistance of fiber-reinforced polymers by simulating the load application in an anterior tooth ${ }^{17}$. An oblique force $\left(45^{\circ}\right)$ applied on the post generated tensile stresses on the outer surface and compression stresses on the interior surface causing a dislodgement of the fiber/matrix interface in the center of the specimen and consequently failure by shear stresses ${ }^{12,15}$. Besides, using finite element analysis, Wandscher et al. ${ }^{12}$ (2015) showed that shear stress on fiber-reinforced polymers is the highest in the center of the specimens and null on the extremities, justifying the failure pattern obtained in the current study. Furthermore, Marchionatti et al. ${ }^{14}$ (2014) evaluated the fracture resistance of teeth restored with fiber posts and composite cores and showed that this type of failure also occurs when teeth are restored with fiber posts. Another factor that could influence this type of failure (fiber/matrix interface) is the different elastic moduli between glass fibers and the matrix, because when a load is applied, the stresses converge to this interface ${ }^{8}$.

An important limitation of the current study is that the test evaluated only the mechanical properties of the posts, thus, the clinical significance is to better know the mechanical properties of GFPs. In addition, the posts were submitted only to static loads and this does not occur clinically. Fatigue tests simulate the clinical situation better, because cyclic loads are applied simulating the chewing ${ }^{22,23}$. Until now, studies are not available that show how much load support an endodontically treated tooth restored clinically with fiber post. In vitro studies as well as clinical studies evaluating the fracture and fatigue of endodontically treated teeth restored with posts are recommended.

In conclusion, despite the diameter of the glass fiber posts being the same, fracture resistance is brand-dependent.

\section{ACKNOWLEDGEMENTS}

The authors state that there is no conflict of interests. We thank to dental store Dental Cremer for materials donation. 


\section{REFERENCES}

1. Assif D, Gorfil C. Biomechanical considerations in restoring endodontically treated teeth. J Prosthet Dent. 1994;71:565-7. doi:10.1016/0022-3913(94)90438-3.

2. Baldissara P. Mechanical properties and in vitro studies. In: Ferrari M, Scotti R, editors. Fiber Posts: characteristic and clinical aplication. Milan: Masson; 2003. p. 39-51.

3. Newman MP, Yaman P, Dennison J, Rafter M, Billy E. Fracture resistance of endodontically treated teeth restored with composite posts. J Prosthet Dent. 2003 Apr;89(4):360-7. doi:10.1067/mpr.2003.75.

4. Vallittu PK. Curing of a silane coupling agent and its effect on the transverse strength of autopolymerizing polymethylmethacrylate-glass fibre composite. J Oral Rehabil. 1997 Feb;24(2):124-30.

5. Bergoli CD, Brondani LP, Wandscher VF, Pereira G, Cenci MS, Pereira-Cenci T, et al. A Multicenter Randomized Double-blind Controlled Clinical Trial of Fiber Post Cementation Strategies. Oper Dent. 2018 Mar/Apr;43(2):128-35. doi:10.2341/16-278-C.

6. Gómez-Polo M, Llidó B, Rivero A, Del Río J, Celemín A. A 10-year retrospective study of the survival rate of teeth restored with metal prefabricated posts versus cast metal posts and cores. J Dent. 2010;38:916-20. doi:10.1016/j.jdent.2010.08.006.

7. Sarkis-Onofre R, Fergusson D, Cenci MS, Moher D, Pereira-Cenci T. Performance of Post-retained Single Crowns: A Systematic Review of Related Risk Factors. J Endod. 2017;43:175-83. doi:10.1016/j.joen.2016.10.025.

8. Lassila LVJ, Tanner J, Le Bell A-M, Narva K, Vallittu PK. Flexural properties of fiber reinforced root canal posts. Dent Mater. 2004 Jan;20(1):29-36.

9. Vallittu PK. The effect of glass fiber reinforcement on the fracture resistance of a provisional fixed partial denture. J Prosthet Dent. 1998 Feb;79(2):125-30.

10. Seefeld F, Wenz H-J, Ludwig K, Kern M. Resistance to fracture and structural characteristics of different fiber reinforced post systems. Dent Mater. 2007 Mar;23(3):265-71. doi:10.1016/j.dental.2006.01.018.

11. Söderholm KJ, Shang SW. Molecular orientation of silane at the surface of colloidal silica. J Dent Res. 1993;72(6):1050-4. doi:10.1177/00220345930720061001.

12. Wandscher VF, Bergoli CD, de Oliveira AF, Kaizer OB, Souto Borges AL, Limberguer $\mathrm{IF}$, et al. Fatigue surviving, fracture resistance, shear stress and finite element analysis of glass fiber posts with different diameters. J Mech Behav Biomed Mater. 2015 Mar;43:69-77. doi:10.1016/j.jmbbm.2014.11.016.

13. Wandscher V, Bergoli C, Limberger I, Cenci T, Baldissara P, Valandro L. Fractographical Analysis and Biomechanical Considerations of a Tooth Restored With Intracanal Fiber Post: Report of the Fracture and Importance of the Fiber Arrangements. Oper Dent. 2016;41:E149-58. doi:10.2341/15-262-S.

14. Marchionatti AME, Wandscher VF, Broch J, Bergoli CD, Maier J, Valandro LF, et al. Influence of periodontal ligament simulation on bond strength and fracture resistance of roots restored with fiber posts. J Appl Oral Sci. 2014 Sep-Oct;22(5):450-8.

15. Pereira GKR, Lançanova M, Wandscher VF, Kaizer OB, Limberger I, Özcan M, et al. Fiber-matrix integrity, micromorphology and flexural strength of glass fiber posts: Evaluation of the impact of rotary instruments. J Mech Behav Biomed Mater. 2015;48:192-9. doi:10.1016/j.jmbbm.2015.04.008. 
16. Wandscher V, Bergoli C, Limberger I, Ardenghi T, Valandro L. Preliminary Results of the Survival and Fracture Load of Roots Restored With Intracanal Posts: Weakened vs Nonweakened Roots. Oper Dent. 2014;39:541-55. doi:10.2341/12-465.

17. Asmussen E, Peutzfeldt A, Heitmann T. Stiffness, elastic limit, and strength of newer types of endodontic posts. J Dent. 1999;27(4):275-8.

18. Grandini S, Goracci C, Monticelli F, Tay FR, Ferrari M. Fatigue resistance and structural characteristics of fiber posts: three-point bending test and SEM evaluation. Dent Mater. 2005;21(2):75-82. doi:10.1016/j.dental.2004.02.012.

19. Monticelli F, Toledano M, Osorio R, Ferrari M. Effect of temperature on the silane coupling agents when bonding core resin to quartz fiber posts. Dent Mater. 2006;22:1024-8. doi:10.1016/j.dental.2005.11.024.

20. Obukuro M, Takahashi Y, Shimizu H. Effect of diameter of glass fibers on flexural properties of fiber-reinforced composites. Dent Mater J. 2008;27(4):541-8.

21. Cheleux N, Sharrock PJ. Mechanical properties of glass fiber-reinforced endodontic posts. Acta Biomater. 2009;5(8):3224-30. doi:10.1016/j.actbio.2009.04.008.

22. Cohen BI, Deutsch AS, Musikant BL. Cyclic fatigue testing of six endodontic post systems. J Prosthodont. 1993;2(1):28-32.

23. Wiskott HW, Nicholls JI, Belser UC. Stress fatigue: basic principles and prosthodontic implications. Int J Prosthodont. 1995;8(2):105-16. 